\title{
Modelo evolucional de competências interculturais de alunos chineses de PLA: comunidade de aprendizagem em tandem para a era de Pós-Covid-19
}

\author{
Hanzi Zhang ${ }^{1}$ \\ Universidade de Estudos Estrangeiros de Tianjin, Tianjin, China
}

Resumo: Dentro da estrutura de um projeto-piloto chinês-português, durante a pandemia de Covid19, foi criado um espaço de "comunidade de aprendizagem" por meios telecolaborativos online, ou tandem, o qual resulta de uma experiência com sessões sucessivas em que os alunos chineses de PLA (Português Língua Adicional) interagem com alunos portugueses de chinês. Levando em conta o processo evolutivo a partir do etnocentrismo até ao relativismo (BENNETT, 1993), propõe-se no presente trabalho, uma novidade, que é existência de uma linha de progressão que ilustra uma evolução multidimensional das competências interculturais, pela análise qualitativa dos dados coletados. A pesquisa qualitativa revela que, a evolução das competências interculturais é estruturada num modelo composto por cinco dimensões, nomeadamente o diálogo, a comunicação, a língua, a introspetiva e o relacionamento, com uma ênfase colocada nas relações interpessoais. O presente estudo procura assim perspetivar uma cidadania global e ao mesmo tempo localizada, com caraterísticas de $\mathrm{He}$ e $\mathrm{Li}$ de doutrina confuciana chinesa.

Palavras-chave: Competências interculturais; Comunidade de aprendizagem; Alunos chineses; Evolução; PLA.

Title: Developmental model of intercultural competencies of Chinese PAL students: tandem learning community for the Post-Covid-19 era

Abstract: By conducting a Chinese-Portuguese pilot project, during the Covid-19 pandemic crisis, a "learning community" space was created by online telecollaborative means, or tandem. The experience results from successive sessions in which Chinese students with Portuguese as an additional language (PAL) interact with Portuguese students with Chinese as an additional language. Taking into account the evolutionary process from ethnocentrism to relativism (BENNETT, 1993), through the qualitative analysis of collected data, a new finding is proposed in the present work, which is the existence of a line of progression that illustrates a multidimensional evolution of intercultural competences. The qualitative research reveals that, the evolution of intercultural competences is structured in a model composed of five dimensions, namely dialogue, communication, language, introspective and relationship, with an emphasis placed on interpersonal relationships. The present study thus seeks to envisage a global and localized citizenship, with characteristics of $\mathrm{He}$ and $\mathrm{Li}$ of Chinese Confucian doctrine.

Keywords: Intercultural competencies; Learning community; Chinese students; Development; PAL.

\footnotetext{
${ }^{1}$ Doutora em Estudos de Linguística (Universidade de Lisboa). Docente da Universidade de Estudos Estrangeiros de Tianjin. Orcid: http://orcid.org/0000-0001-8344-734. E-mail: zhang.hanzi@yahoo.com
} 


\section{Introdução}

$\mathrm{Na}$ globalização omnipresente e em constantes mudanças, a divulgação do ensinoaprendizagem de Português Língua Adicional (PLA) tem acompanhado este mundo. No entanto, a realidade é que o ensino de qualquer língua adicional (LA) não se faz só para capacitar os alunos com fluência ou correção de uma língua, mas também pela concretização de comunicação intercultural interagindo com falantes de outras culturas, de outras identidades. Assim, para se tornar um mediador intercultural pede-se não só a aquisição de LA, mas também o desenvolvimento de competências interculturais (doravante designadas por $\mathrm{Cl}$ ), uma outra expressão de cidadania global de acordo com Deardorff (2015). A discussão na comunidade acadêmica tem sido ainda mais motivada pelo aumento significativo da procura de intercâmbios universitários, um fenômeno que devido ao seu funcionamento deve preocupar os professores e investigadores da área, precisamente com as competências em falta para um encontro intercultural. Neste aspeto, assume-se que esta questão é mais relevante e oportuna dadas as peculiaridades relacionadas com os encontros orienteocidente, encontros que se tornam essenciais para a educação de cidadania ativa intercultural.

Entre os trabalhos colaborativos e seriados de autores orientais e ocidentais, GuoMing Chen e William J. Starosta (1996) definem a Cl como "habilidade de negociar significados culturais e conduzir comportamentos comunicativos de forma apropriada e eficaz, que reconhece as múltiplas identidades dos interlocutores num ambiente específico"3 ${ }^{3}$ (p. 358359). Em outras palavras de Chen e Starosta (1998-9), é a habilidade de reconhecer, de respeitar, de tolerar e de integrar as diferenças culturais, a qual nos permite qualificando com uma cidadania global. Trata-se de uma afirmação que valoriza a interação eficaz e apropriada entre os interlocutores interculturalmente competentes, em que são indispensáveis a sensibilidade afetiva, a consciência cognitiva e a habilidade comportamental. Estes interlocutores, dotados de $\mathrm{Cl}$, sabem "como obter uma resposta desejada em interações e cumprir seus próprios objetivos comunicativos, respeitando e afirmando as visões do mundo e identidades culturais de outros interlocutores"4 (CHEN; STAROSTA, 1998, p. 28). Dizendo isto e tendo em conta o público-alvo com quem trabalhamos todos os dias, que são os alunos universitários chineses de PLA, a necessidade aponta para uma modelização esclarecedora de $\mathrm{Cl}$, do nosso público, assim como a compreensão da sua evolução no encontro com uma cultura não muito próxima.

Uma das questões mais relevantes hoje em dia é que, as caraterísticas de Covid-19, particularmente o seu potencial de transmissibilidade, tornam ainda mais imprescindível um planejamento estruturado para cenários variados nesta emergência de saúde pública. Nesta

\footnotetext{
2 Este artigo foi realizado no âmbito do projeto TJYYQN20-006, "Desenvolvimento de Competências Interculturais para as Línguas não Comuns em Comunidade de Aprendizagem", financiado pela Câmara Municipal de Tianjin.

3 Tradução minha de "the ability to negotiate cultural meanings and to execute appropriately effective communication behaviors that recognize the interactants' multiple identities in a specific environment".

${ }^{4}$ Tradução minha de "how to elicit a desired response in interactions and to fulfill their own communication goals by respecting and affirming the worldviews and cultural identities of the other interactants".
} 
conjuntura de alterações e revoluções, os constrangimentos evidenciam as incertezas dos programas de cooperação ou de intercâmbios universitários. Com o intuito de preparar a resposta e minimizar o impacto da pandemia de Covid-19, em particular, prevendo as circunstâncias na era de Pós-Covid-19, chega o momento premente para a ponderação dos novos modelos de trocas ou comunicações no espaço mais alargado. São os esforços que permitem aos jovens de hoje abandonar os preconceitos e desentendimentos, que neste mundo de crise ocorrem com maior frequência e, inquestionavelmente, as novas tecnologias de informação facilitam a aplicação e a atualização desses modelos a distância. Os princípios da aprendizagem em tandem, designadamente, a autonomia, a reciprocidade e a autenticidade (GONÇALVES, 2019) levam-nos a refletir sobre a possibilidade de, perante os desafios da crise atual e da era de Pós-Covid-19, estabelecer uma comunidade de aprendizagem, recorrendo à telecolaboração, com o eixo principal na promoção de $\mathrm{Cl}$ pertinente.

\section{Questões da investigação}

Os objetivos a que pretendemos chegar norteiam a elaboração das questões principais desta investigação, que, da mesma forma, justificam a opção de metodologia qualitativa do estudo e de abordagem em aula de português, junto do nosso público-alvo. Com base nisto, apresentamos em seguida as questões da investigação:

a) Quais são as especificidades que caraterizam o modelo de $\mathrm{Cl}$ dos alunos chineses de PLA?

b) De que forma se deve estabelecer o novo modelo de ensino-aprendizagem para a era de Pós-Covid-19 e quais perspectivas com o desenvolvimento de $\mathrm{Cl}$ mediante isto?

\section{Modelos de $\mathrm{Cl}$}

Nesta seção serão apresentados os fundamentos teóricos sobre os modelos de $\mathrm{Cl}$, com mais destaque nos modelos evolucionais e a discussão mais alargada sobre a questão pode ser encontrada no trabalho de Zhang (2019). Geralmente, os modelos exteriorizam, de forma simples, os comportamentos complexos dos seres humanos (BRISLIN; YOSHIDA, 1994). Este é o caso dos modelos de $\mathrm{Cl}$ que, pela sua natureza, tem sido continuadamente apreciado e desenvolvido no mundo acadêmico visando uma descrição inteligível da complexidade das competências na comunicação intercultural. Do mesmo modo, de acordo com a revisão de Spitzberg e Changnon (2009), não estão terminados os esforços de estruturação de modelos de $\mathrm{Cl}$, em particular, os que se ocupam da caraterização de contextos específicos. Entre eles estão os investigadores da área educacional, de negócios e de serviços, de conflitos, de assistência médica, de adaptação internacional, de imigração, de organização e gestão. A pesquisa feita pelos autores $(2009$, p. 7), segundo uma ordem cronológica, sobretudo no que diz respeito às teorizações e modelizações de $\mathrm{Cl}$, aponta "uma progressão de modelos 
individualizados para modelos mais sistêmicos e inclusivos" ${ }^{\prime 5}$. É com base nestes pressupostos, que se chega a uma organização (SPITZBERG; CHANGNON, 2009) em cinco tipologias de modelos de $\mathrm{Cl}$ : os modelos composicionais, os modelos coorientadores, os modelos evolucionais, os modelos adaptativos e os modelos casuais. Os modelos composicionais identificam os componentes das competências interculturais; os coorientadores geralmente partilham a visão de mutualidade interativa; os adaptativos priorizam os ajustes em processo de adaptação; os modelos causais refletem as relações específicas entre os componentes; os modelos evolucionais reconhecem que as competências evoluem ao longo do tempo e a Cl passa pelas diferenças faseadas.

É de destacar que, mais uma vez, os modelos que aqui são tratados transparecem uma perspectiva ocidental, sendo que, a maior parte deles, nasce predominantemente na cultura anglo-saxônica (SPITZBERG; CHANGNON, 2009). Além disso, muitos também são criticados por serem teoricamente fracos uma vez que são modelos, muitas vezes, individual-oriented (MATSUO, 2012) ou reducionistas (MARTIN, 2015) e, assim, é requerida alguma cautela para explicar e prever o seu desenvolvimento de $\mathrm{Cl}$, de modo mais holístico, mais relacional.

À vista disto, os modelos evolucionais predizem e delineiam a natureza evolucional de interação intercultural e, ao mesmo tempo, chamam a atenção para as mudanças processuais em jogo nesta interação, do mesmo modo que podem funcionar os treinamentos e os cursos para esse fim. Considerando as críticas feitas principalmente em relação aos modelos composicionais assim como os outros na cultura anglo-saxônica e não negligenciando o contexto específico neste âmbito, o modelo evolucional evidencia-se aqui apropriado e pertinente para sustentar o enquadramento e a teorização do presente estudo.

Em poucas palavras, os modelos evolucionais reconhecem que as competências evoluem ao longo do tempo e a $\mathrm{Cl}$ sucessivamente sofre diferenças faseadas. Bennett (1993) conceitua a $\mathrm{Cl}$ como um modelo de desenvolvimento (Development Model of Intercultural Sensitivity, DMIS), no qual os indivíduos progridem ao longo de um continuum em direção ao objetivo de "successful acquisition of the international perspective" (p. 24). Assim, o modelo de Bennett baseia-se numa evolução, semelhante àquela em que os indivíduos passam com as diferenças culturais, que é composta por três fases etnocêntricas (negação, defesa, minimização) e três etnorelativas (aceitação, adaptação, integração). Da mesma forma, a interpretação do autor é adequada à formação da Cl. Hammer e Bennett (2001) adaptam e conseguem ter um novo modelo (IDI, Intercultural Development Inventory), em que um indivíduo experiencia um continuum que liga a monocultura com a cultura intercultural, nas definições como designam os autores. King e Baxter Magolda (2005), através da identificação dos níveis inicial, intermediário e maduro do desenvolvimento intercultural, procuram salientar o processo até atingir a maturidade em aspetos cognitivo, intrapessoal e interpessoal. O projeto ICOPROMO (2007) também classifica o desenvolvimento de $\mathrm{Cl}$ num modelo transformacional. O outro exemplo é o mais recente, Holmes e O'Neill (2012) e Arasaratnam (2015) apresentaram o novo modelo abreviado por PEER: preparing, engaging,

\footnotetext{
${ }^{5}$ Tradução minha de "a progression from individual-based models to more systemic and inclusive models".
} 
evaluating, reflecting, visando, desta maneira, o processo integrativo e repetitivo do desenvolvimento de $\mathrm{Cl}$. Além destes estudos que objetivam um público bem geral e alargado, há alguns representativos que se encaixam nos contextos específicos como o modelo de Kedia e Mukherji (1999) no contexto de negócios (de conflitos à participação), o de Banks (1994) de posicionamento (de nacionalismo até às competências globais). São modelos, direta ou indiretamente influenciados por Bennett (1993), que têm a maior cobertura de público-alvo. Tendo em conta este contexto teórico, o presente estudo optou por uma pesquisa qualitativa e acabou por apresentar o modelo próprio, baseando nas palavras-chave da pesquisa.

\section{Desenvolvimento de modelos de $\mathrm{Cl}$ na China}

As $\mathrm{Cl}$ já foram agregadas em "Padrão Nacional" 6 e consideradas nucleares de ensinoaprendizagem, do mesmo modo estão desenvolvidos na interação com as competências de critical thinking (raciocício crítico) (SHEN; GAO, 2015). Tendo em conta a evolução teórica por mais de seis décadas, as $\mathrm{Cl}$ já fazem uma parte na internacionalização do ensino superior, na iniciativa de "nova Rota de Seda", assim como na nova organização de área de conhecimentos, que inclui as matérias de arte, a proposta levantada com o propósito de um desenvolvimento mais integrado e transdisciplinar da China.

Porém, neste momento, o que está em causa permanece na análise comparativa em termos de semelhanças e diferenças culturais, o que não favorece uma construção aprofundada de cidadania global, em termos práticos. Tal como o mundo ocidental, o modelo composicional de $\mathrm{Cl}$ consiste numa tendência que atrai mais contributos dos acadêmicos chineses. As mais representativas são as classificações de Jia (1997), Wen (1999) e Yang e Zhuang (2007), que possuem um olhar mais ou menos aproximado e compreendem geralmente quatro sistemas ordenados. Um dos exemplificativos dos poucos modelos evolucionais do contexto chinês vem de Gao (2002), que advoga os conceitos de "instrumento" e "Tao" no sentido de favorecer o desenvolvimento das competências de "passar" e de "ultrapassar", tendo o "passar" para adquirir novos conhecimentos e habilidades e o "ultrapassar" para se conscientizar de diferenças e estereótipos culturais de modo a alcançar uma comunicação construtiva.

Neste sentido, é de salientar que a discussão no seio acadêmico chinês não é comparável teoricamente aos pressupostos de perspetivas ocidentais, principalmente por causa de data de início da própria disciplina, daí resulta, apesar das perspetivas distintas, a referência de modelizações ocidentais pelos autores chineses. É claro que o reconhecimento de dimensões dentro dessas modelizações passou pelas examinações práticas no terreno local, com o público-alvo chinês, no entanto, são previstos mais debates em redor da comunicação "apropriada" intercultural, assim como a modelização localizada, mais atenta à realidade da China (DAI, 2019).

\footnotetext{
${ }^{6}$ Padrão Nacional para os Cursos de Licenciatura de Cursos de Língua Estrangeira em Instituições do Ensino Superior (2018), que inclui pela primeira vez uma definição de Cl no ensino-aprendizagem de línguas, a nível nacional da China.
} 
No entanto, os autores e estudos acima referidos são majoritariamente conquistas no mundo acadêmico chinês, com o seu foco de estudo na língua inglesa, a LA designada como "comum" na China. Resta-nos conduzir investigações em relação ao enquadramento teórico e à avaliação de $\mathrm{Cl}$ dos aprendentes de LA "pouco comum", tampouco conhecemos estudos empíricos suficientes que consigam manifestar as regras de evolução de $\mathrm{Cl}$ entre os aprendentes chineses. Ao mesmo tempo, percebemos que o ensino-aprendizagem de PLA, uma das línguas pouco comuns na China, deve projetar o caminho de desenvolvimento mais direcionado para a realidade do país e, simultaneamente, interculturalmente desenhado e praticado com uma participação mais ampla de aprendentes, de modo a os capacitar com as $\mathrm{Cl}$ além das linguísticas. Este caminho leva a uma modelização indicada para o propósito, que neste caso se identifica como uma lacuna a ser colmatada. Em seguida, será apresentada a metodologia com uma experiência de comunidade de aprendizagem em tandem, a qual consiste numa investigação qualitativa.

\section{Comunidade de aprendizagem em tandem de PLA}

Comunidade de aprendizagem: os princípios

O construtivismo na aprendizagem advoga a construção de novas experiências na base daquelas já adquiridas. O construtivismo individual e o social são as duas vertentes que servem para entender o conceito. No processo de aprendizagem, o indivíduo passa pelas interações e integrações dos conhecimentos "novos" e "velhos", dessa forma, são atribuídas novas modificações para ambos os conhecimentos. Constituem o ponto de partida apenas os conhecimentos ou experiências que detém anteriormente, de maneira a construir o seu modelo mental mais abrangente e completo. Por sua vez, o construtivismo social introduz no processo de aprendizagem uma participação multicultural, a comunidade de aprendizagem neste caso é onde acontece a tal construção de conhecimentos, uma vez que não se defende aqui uma aprendizagem de forma passiva, mas sim os saberes de como adquirir e analisar via a cooperação. Na sequência disto, a comunidade de aprendizagem segue também os princípios de tandem que, por sua natureza, pode ser entendido como "a bonita imagem de uma bicicleta para duas pessoas, [...], em que as ciclistas só têm êxitos se os dois colaborativamente pedalaram ao mesmo tempo e para o mesmo lado, [...]" (GONÇALVES, 2019). Assim sendo, trata-se dos princípios orientadores estas visões de conhecimento, de aprendizagem e de ensino na nossa construção de comunidade, durante a qual, o contexto, a cooperação, o diálogo e a construção de significados são os elementos indispensáveis para a concretização da nossa proposta de projeto.

Acresce que, apesar de neste momento a educação ter sofrido bastantes constrangimentos - incertezas de programas de intercâmbio dos corpos docente e discente, provocadas pela crise sanitária, a comunidade de aprendizagem em tandem aparece como uma alternativa que corresponde às atuais incertezas. Pela nossa revisão de literatura, vemos por exemplo a avaliação de Wang e Kulich (2015), na qual os alunos envolvidos em interações 
de diversidade cultural doméstica e em intercâmbios interculturais online conseguiram tantos avanços na $\mathrm{Cl}$ quanto aqueles que se envolveram em encontros interculturais face a face.

\section{Comunidade de aprendizagem: as práticas}

Neste enquadramento da era informática, a comunidade de aprendizagem tomou a forma virtual pretendendo servir assim como uma plataforma de diálogos e comunicações entre os alunos chineses e estrangeiros. Tornou-se ainda mais pertinente essa comunidade de aprendizagem pelo que se provoca pelo ensino-aprendizagem a distância nesta nova emergência de saúde pública. Essa proposta de transformação educacional no ensinoaprendizagem de PLA visa a partilha e a estruturação de conhecimentos, assim como a comunicação intercultural e a consequente reflexão. O projeto leva particularmente em consideração a natureza cognitiva e interpessoal no seu planejamento. Neste âmbito, para o maior equilíbrio da comunidade e a credibilidade da iniciativa, duas turmas, uma de curso de português na China e a outra de curso de chinês em Portugal constituem uma opção justificada para o efeito. ${ }^{7}$ Desta forma, durante os meses de fevereiro, março, abril, maio de 2020, 27 alunos chineses e 27 alunos portugueses entraram no projeto com uma participação focada em tarefas, pelo conjunto de atividades que se promovem a mutualidade de aprendizagem, de influência e de crescimento. Em um caso como este, o papel de professor passa para promotor de tal aprendizagem, de maneira que os casos ou exemplos concretos são concebidos na tentativa de incentivar os modos variáveis de pensar e opinar dos alunos. Em poucas palavras, informações fornecidas vêm provocar discussões profundas, fazendo as interações entre o que já conhece e o que ainda não conhece, entre a problemática do mundo verdadeiro e as soluções possíveis. A criação desta nova construção social de aprendizagem é individualizada e a combinação das duplas é feita considerando os interesses e expectativas dos alunos, tudo apontando para a atuação e para a cooperação ativas nesta comunidade virtual.

Olhando mais detalhadamente para a concretização do projeto, o projeto foi constituído por quatro sessões, ou por outras palavras, quatro tarefas, que demoraram, cada uma, uma hora de interações orais. O processo completo de interação de uma tarefa é composto por fases de pré-atividade, atividade e pós-atividade. Na fase de pré-atividade, o formador apresentou os casos introdutórios, bem como umas linhas orientadoras para a discussão como as perguntas refletivas. Por sua vez, os alunos fazem preparativos que devem incluir a coleta de informações relacionadas com a cultura do outro e a própria cultura e, de perguntas a ser refletidas/discutidas/entrevistadas. A seguir, os diálogos, que são a parte nuclear, são conduzidos tanto em português como em chinês, as competências de apresentar, analisar, sugerir e comparar são algumas que merecem mais desenvolvimento nesta fase. As pós-atividades são compostas por dois passos, a iniciar pela apresentação de um ensaio comparatista intercultural, um produto conjunto desta comunidade. Por fim, em aula de

\footnotetext{
7 O projeto de pesquisa foi submetido e aprovado pelo comitê de ética, tendo sido certificado sob o no XSDD20200118.
} 
português uma retrospetiva do processo de aprendizagem é feita em parceria entre o formador e os alunos chineses, e estes, com base nisto, submetem os seus relatórios reflexivos.

Geralmente a avaliação por tarefa é feita por formador na base de leitura destes dois documentos, um ensaio e um relatório reflexivo, neste caso, a avaliação contínua é algo essencial, não negligenciando as oportunidades de os alunos exprimirem as suas autoavaliações. Desta forma, segue-se o modo de funcionamento de cada sessão.

Quadro 1 - Modo de funcionamento de cada sessão

\begin{tabular}{|llll|}
\hline Pré-atividade & Atividade & Pós-atividade & \\
\hline Lançamento e & Telecomunicação & Ensaio & Discussão face-a-face \\
preparação de & por Wechat & comparatista & Relatório reflexivo \\
atividades & & & avaliação \\
\hline
\end{tabular}

Fonte: Elaborado pela autora

Comunidade de aprendizagem: coleta de dados

Os dados do presente estudo nasceram maioritariamente dos ensaios comparatistas e relatórios reflexivos, por parte dos alunos, e dos diários registados por parte do próprio formador. Prolongando-se por um semestre inteiro, foram, no total, colecionados 108 ensaios comparatistas e 108 relatórios reflexivos dos aprendentes chineses, assim como as gravações de interações orais, de 6.480 minutos. Também foram colecionadas informações reveladoras na base da conduta das entrevistas semiestruturais com os participantes selecionados. Essas entrevistas compreendem, principalmente, umas retrospetivas dos participantes na comunidade de aprendizagem, nas quais foram relatadas as alterações, por sessões, e sobretudo as evoluções em seu todo. Cerca de meia hora dura cada entrevista, que, por consentimento dos participantes, foi gravada e depois transcrita.

Comunidade de aprendizagem: análise de dados

Todos os documentos acima referidos, separados por sessão e tratados com corpus do presente estudo, foram codificados e passados pelas-análises prévias. Em seguida, eles foram introduzidos no programa Nvivo11.4, processados e analisados neste programa também. Após as leituras repetidas, interpretações e induções, com referência a grounded theory (STRAUSS; COBIN, 1990), a análise de dados procura identificar sistematicamente um quadro de categorias agregadas, de forma que os significados dos dados são qualitativamente bem descritos. 


\section{Análise dos dados}

Como já foi explanado anteriormente, os dados do presente estudo são retirados das quatro tipologias de documentos, entre os quais são concluídas 76 palavras-chave para a primeira sessão, 46 para a segunda, 44 para a terceira e 47 para a quarta. Todas as palavras são revistas com o intuito de excluir aquelas idênticas ou semelhantes. As palavras-chave convergem para o ressurgimento ou a descoberta de 3 passos de evolução, interligados por quatro sessões. Por exemplo, a afirmação "o que eu fiz bem e que pretendo continuar é ter small talks antes de entrarmos em diálogos, [...]." (Entrevista № 2) manifesta o incentivo unilateral de aluno, considerado como o 10 passo de evolução de $\mathrm{Cl}$. Olhando do ponto de vista macro, este 10 passo insere-se na evolução da forma de diálogo. Da mesma maneira, pode-se identificar que a evolução acontece em cinco aspetos, que serão chamados em dimensões neste estudo.

Tabela 1 - Três passos de evolução por dimensão

\begin{tabular}{|c|c|c|c|c|c|}
\hline Dimensões & 1a evolução & $\rightarrow$ & 2a evolução & $\rightarrow$ & 3a evolução \\
\hline 1. Diálogo & $\begin{array}{l}\text { Incentivo } \\
\text { unilateral }\end{array}$ & $\rightarrow$ & $\begin{array}{l}\text { Maior } \\
\text { autenticidade }\end{array}$ & $\rightarrow$ & $\begin{array}{l}\text { Modo de } \\
\text { relacionamento }\end{array}$ \\
\hline 2. Comunicação & $\begin{array}{l}\text { Produção } \\
\text { bloqueada }\end{array}$ & $\rightarrow$ & $\begin{array}{l}\text { Partilha de } \\
\text { conhecimentos }\end{array}$ & $\rightarrow$ & $\begin{array}{l}\text { Modo de } \\
\text { pensar }\end{array}$ \\
\hline 3. Língua & $\begin{array}{l}\text { Competências } \\
\text { linguísticas }\end{array}$ & $\rightarrow$ & $\begin{array}{l}\text { Subida de } \\
\text { qualidade }\end{array}$ & $\rightarrow$ & $\begin{array}{l}\text { Carater } \\
\text { instrumentalista }\end{array}$ \\
\hline 4. Introspetiva & $\begin{array}{l}\text { Reflexão } \\
\text { multilateral }\end{array}$ & $\rightarrow$ & $\begin{array}{l}\text { Concretização de } \\
\text { reflexão }\end{array}$ & $\rightarrow$ & $\begin{array}{l}\text { Inclusividade } \\
\text { crítica }\end{array}$ \\
\hline 5. Relacionamento & $\begin{array}{l}\text { Ajuste } \\
\text { psicológico }\end{array}$ & $\rightarrow$ & $\begin{array}{l}\text { Estabelecimento } \\
\text { de parceria }\end{array}$ & $\rightarrow$ & $\begin{array}{l}\text { Língua } \\
\text { comum }\end{array}$ \\
\hline
\end{tabular}

Fonte: Elaborada pela autora.

Aqui, é estruturado o modelo evolucional de competências interculturais de alunos chineses de PLA, tal como se demonstra pela Figura 1. Sendo que a língua, neste caso o PLA, como uma dimensão de $\mathrm{Cl}$, passa também por um processo de evolução. Deste jeito, ressaltamos que, dentro da comunidade de aprendizagem, as competências interculturais de alunos evoluem-se_nas cinco dimensões categorizadas, com as competências linguísticas de PLA, lado a lado. 
Figura 1 - Modelo evolucional de competências interculturais

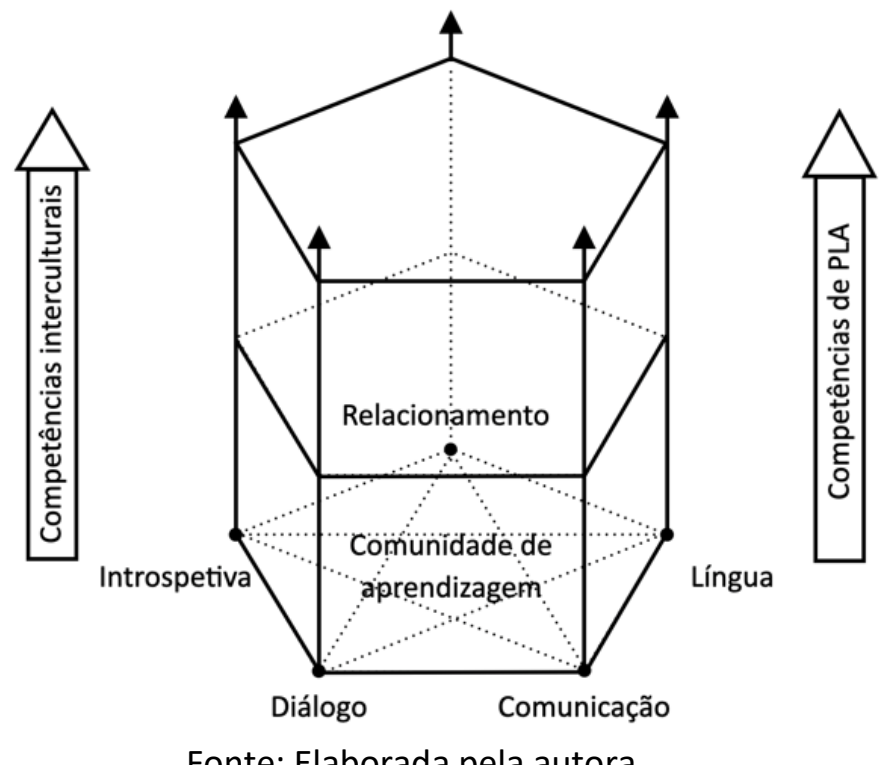

Fonte: Elaborada pela autora.

Sobre o diálogo

Logo no início da iniciativa, não excluindo outras consequências, a comunidade de aprendizagem em tandem potencia uns encontros "estressados", "embaraçosos" e até "torturados" para os alunos chineses. Tais sensações surgem na sequência da falta de confiança principalmente nas competências linguísticas de português, pelo que são relatadas as preparações minuciosas para o diálogo e as interações pobremente interativas. Muitos confessam ter preparado as perguntas e respostas em antecedência, fazendo com que as produções orais dos nossos inquiridos não sejam de modo nenhum espontâneo, o objetivo é evitar erros linguísticos e a perda de tempo no decorrer de diálogos, que neste caso, não se identificam como diálogos verdadeiros. Os encontros virtuais continuam a ser distanciados pela elaboração cuidadosa e detalhista de cada tarefa. Porém, as situações melhoram na última sessão, em que a familiarização pessoal dentro da comunidade traduz-se em mais tópicos alargados, mais rodas de perguntas e respostas, em suma mais interações nos diálogos. As reações cada vez mais instintivas e naturais ajudam a encontrar os temas preferidos por ambas as partes, provocando a "crescente duração de diálogos" e uma "satisfação com organização de diálogos". O excerto abaixo ilustra como o aluno está frustrado perante a situação difícil na primeira sessão.

Parece-me que estivemos confinados aos materiais existentes, sem exploração nem nada mais. Provavelmente foi por causa da preparação insuficiente da minha parte, até ficava com boquiaberta muitas vezes por não saber como me exprimir. Acho que devemos, eu e a minha parceira do grupo, ter uma ideia mais ou menos concordada sobre a divisão do tempo. 
Desta vez, disse as minhas opiniões durante a primeira metade do tempo e ela, na segunda metade, assim não é um diálogo. Não há uma interação. ${ }^{8}$ - Relatório reflexivo № 14 , 1 a sessão

No entanto, essas sensações de frustração estão longe de prejudicar as iniciativas tomadas pelos nossos participantes face aos diálogos, tampouco afetam a participação ativa em diálogos sucessivos. O testemunho abaixo comprova uma melhor autoavaliação de qualidade de diálogo, baseando no maior incentivo e na maior autonomia do próprio aluno.

O que eu fiz bem e que pretendo continuar é ter small talks antes de entrarmos em diálogos, uma vez que são as pequenas trocas de palavras sem apoio de materiais nem de preparação prévia. Trata-se de um teste verdadeiro da minha capacidade e flexibilidade de aplicação de língua. O outro ponto que vale a ser realçado é que, durante o diálogo, tentei a não olhar para minhas escritas e fiz comentários logo que surgiram ideias oportunas, o que me fez sentir bastante desafiado mas ao mesmo tempo estimulado. Entrevista $n$ o 2.

A autenticidade do contexto é também o outro fato que provoca grandes perturbações entre os inquiridos. Eles, ao perceberem os seus déficits linguísticos, procuram soluções por meio de repetições ou outros recursos adicionais, recursos que não permitem a fluidez e a naturalidade de diálogos. Paralelamente, é inegável os esforços de adaptação dos alunos chineses ao contexto, que, por sua vez, transmitem uma clara evolução de $\mathrm{Cl}$ face ao mundo real. Veja como o aluno é confrontado com o português idêntico.

Devo dizer que, pela primeira vista, fiquei chocada com a velocidade de discurso dela. Isso fez-me entender o que se tratava de um diálogo verdadeiro com estrangeiros (totalmente diferente das nossas aulas de audição com gravações de áudio ou vídeo). Na situação como esta, percebi que os portugueses pronunciam de uma maneira muito levezinha e rápida, às vezes acompanhados por tons que imagino exprimir algo, até ao certo ponto deixando-me só conseguir pegar umas palavras e não a sua ideia geral. O outro é o seu modo de falar. Nesta circunstância, descobri certas diferenças entre o que nós já aprendemos e o que os portugueses realmente diziam. São as diferenças que me dificultavam o entendimento do diálogo. Será que eles não respeitam a gramática? - Ensaio comparatista №26, 3a sessão

O uso de expressões idiomáticas e o evitar de erros pragmáticos facilitam a comunicação rumo a um melhor relacionamento interativo. No presente estudo, reciprocamente são oferecidos andaimes de aprendizagem um ao outro, caraterísticos de tandem, algo parecido com a "zona de desenvolvimento proximal" de Vygotsky (1978). Da mesma forma o desenvolvimento de $\mathrm{Cl}$ vai-se junto ao desenvolvimento integral de cada indivíduo, aí se geram o prazer de dialogar, de comunicar e de conviver. Os diálogos funcionam, na última sessão, como um dos modos de relacionamentos entre alunos.

A nossa conversa desta vez faz-nos aproximar e a nossa amizade avançar. Ao longo da conversa encontrámos muitos tópicos que iam ao nosso interesse, razão pela qual me parecia mais como um diálogo e não uma entrevista como tinha acontecido antes. Apliquei assim que aprendi algo. - Relatório reflexivo №19, 4aㅗ sessão

\footnotetext{
${ }^{8}$ Todos os testemunhos aqui relatados, em itálico, são originalmente em chinês e de tradução minha.
} 
Sobre a comunicação

Olhando mais precisamente para o que é comunicado, é fácil discernir a situação constrangedora dos alunos. Neste aspeto, as tarefas e perguntas previamente delineadas pela própria formadora não ajudam muito. Há os casos isolados que a comunicação não ocorre oralmente, onde os alunos substituem por trocas escritas com o propósito de fugir dos "imprevisíveis". Acresce que favorece essa opção dos alunos o desequilíbrio em termos de nível de língua dentro de uma comunidade. Na primeira sessão, é comum encontrar as conversas bloqueadas dos alunos.

Aliás, antes do diálogo, preparei tudo e até escrevi tudo que tinha de responder em papel. Receava que me esquecesse de tudo na hora de diálogo sob uma grande pressão. Os resultados mostraram que isso foi apenas uma perda de tempo e não ajudou nada. Eu fui péssima. Ao longo da conversa não tive nem um minuto estando cômoda com a situação, mesmo prestando toda a minha atenção, o português dele conseguiu escapar meus ouvidos. Julgo que foi uma conversa caraterizada só por momentos de silêncio embaraçador. Relatório reflexivo № 15, 1 a sessão

Só com o incentivo da formadora é que os alunos começam a deixar as bengalas como as notas escritas. Assim, a preparação prévia passa a ser mais básica e conta apenas com o brainstorming das palavras-chave. Porém, este desafio lançado pela formadora permite os alunos a tomar os primeiros passos na exploração de novos tópicos e de perguntas espontâneas, o que, de certa maneira, corresponde à necessidade de autenticidade de diálogos. A partilha de conhecimentos parte, neste caso, dos mais familiarizados pelos alunos, tais como os episódios da sua vida diária ou os costumes do seu país. O facto abre espaços para ainda mais partilhas, dando um grande impulso à discussão em si e à $\mathrm{Cl}$. O excerto é um comprovativo dos esforços do aluno em procurar partilhar mais conhecimentos, de forma autêntica.

Preparei muitas notas para a última vez. Nesta vez alterei a estratégia e decidi por enquanto só preparar os vocabulários mais chaves e arrumar os meus raciocínios de forma mais simples. Penso que a partir disto as minhas produções orais se podem considerar como verdadeiras. É claro que vou primeiro me concentrar nos tópicos mais quotidianos, mas sim fora do âmbito dos materiais escolares. - Relatório reflexivo № 22, 2a sessão

Por meio de adaptação aos novos modos de diálogo, a qualidade de comunicação é promovida em companhia do horizonte mais alargado e dos temas mais "interessantes, atualizados e individualizados". É justamente com base na partilha de conhecimentos é que os alunos adquirem novas experiências bem como identificar certas convergências e divergências. Destacamos aqui as que são mais relacionadas com o modo de pensar. De uma forma geral, os alunos passam a ser dotados de uma competência racional de olhar para as questões no seu redor, além de saber refletir os seus modos de ser e de falar. A tal consciência de olhar para si mesmo torna ainda mais óbvia a pertinência de evolução de $\mathrm{Cl}$ entre aprendentes de uma LA. Normalmente, no ensino-aprendizagem de PLA, é mais trabalhado o conhecer sobre o Outro, nomeadamente, a cultura que tem o seu núcleo em português, ao 
passo que o conhecimento sobre o Si é frequentemente esquecido por ser considerado como uma área separada da linguística. Neste sentido, procuramos ter uns bons interlocutores interculturais, que não perdem a sua identidade própria ao interagir com os outros. A Entrevista № 9 compara as diferenças de modos de pensar entre colegas, o que ajuda no seu desenvolvimento de $\mathrm{Cl}$.

É aos assuntos sociais ou estatuais que a minha colega mais refere, ao contrário de mim, que faço questão dos interesses mais individualizados. Tenho a sensação de que as suas respostas são mais profundamente refletidas e depois dadas com a lógica e mais sistematicamente, e a mim, acontecem mais vezes as respostas soltas. Talvez seja assim a nossa diferença, o motivo que me faz querer conhecer mais sobre o modo de pensar dos outros e se assim for necessário, aprender com eles. - Entrevista № 9

\section{Sobre a língua}

Entre a maioria dos diários refletivos da primeira sessão, manifesta-se a deficiência linguística com o maior destaque, desde as incompetências na compreensão e na produção, até aos problemas de "entonação", de "transferência negativa da língua mãe", etc. A sensação que é transmitida aqui é a ansiedade e o anseio por progressos nas competências linguísticas. A perceção generalizada consiste na importância suprema da língua para o sucesso de encontros interculturais, tal como o que se ilustra no excerto abaixo.

Nervoso e entusiasmado, sim, são dois adjetivos que me caraterizavam nos primeiros minutos na nossa primeira chamada. E o meu português era horrível, longe de ser satisfatório, apesar de posteriormente ele ter melhorado pouco a pouco. Quando eu ia dizer algo, perdia a minha memória, até mesmo aquelas palavras mais utilizadas, que estavam na ponta de língua e não saíram. De repente e naquele momento, não veio à mente o que aprendi: a gramática, os tempos verbais, entre outros. Todos verbos conjugavam-se no presente. Eu nessa vez fiquei a conhecer o meu verdadeiro nível de português, sobretudo a oralidade, mesmo que isso não causou grandes desconfortos na compreensão da colega. - Relatório reflexivo № 7, 1a sessão

Uma minoria dos participantes, no entanto, possui umas experiências mais encorajadoras que os outros, que afirma conseguir ter a resposta ativa e positiva aos encontros e consequentemente os resultados aceitáveis. Acontece que, em termos globais, no princípio, concentram-se na questão de língua os diários refletivos, que a partir daí, sustentam novos planos de estudo e novas atividades escolares ou extraescolares, até novas propostas a professores. Pode-se dizer que o projeto nosso thes confere um "grande incentivo" ao estudo universitário.

Contudo, as práticas ao longo da decorrência do projeto veem a deslocação de atenção para o teor de comunicações. Para além da continuada ponderação nas suas competências linguísticas em si, é também tida em conta uma "competência interpretativa", suscetível a colmatar o défice na língua. Aqui a competência pode ser entendida como o saber explicar, negociar e recorrer aos outros apoios verbais ou não verbais no meio de conversa. Desse modo, consciente ou inconscientemente, são omitidos os erros linguísticos que não afetam a 
compreensão, e assim são garantidas a fluência e a duração de diálogo. Mesmo estando a focar no aspeto linguístico, a conclusão tirada refere-se à insuficiência das competências linguísticas para este tipo de encontros interculturais. $O$ excerto revela como o aluno aprende com o seu parceiro, tanto nas competências linguísticas de PLA, como nas competências interpretativas, objetivando a qualidade elevada do diálogo.

Falámos muito, provavelmente por se tratar de um tema bastante discutível. Ao longo destas sessões, vou aprendendo, imitando e aplicando, tal como um círculo jogado entre nós dois. Algumas expressões a mim deixaram mais impressão, sendo que são mais usadas pelo colega e agora sei usá-las com frequência. Já não mais tenho vergonha em pedir as repetições ou explicações dele. - Relatório reflexivo № 19, 3a sessão

Não é difícil argumentar que, pelos testemunhos e na visão dos alunos chineses, a língua passa a assumir um papel alterado. O conhecer do Si e do Outro ajuda a ter uma consciência mais clara sobre a natureza instrumentalista de língua. Assim, já não residindo na língua, o objetivo principal da comunicação intercultural aponta para os verdadeiros propósitos de comunicação. Na Entrevista № 1 é demonstrada a atenção virada desde os erros gramaticais até às ideias transmitidas pela língua, mostrando o seu carater instrumentalista.

A língua é a língua da vida e não é realista aprendê-la fora de contexto. A oportunidade é ótima só que não me apetece dialogar apenas para treinar a oralidade. O que me chama mais atenção são os valores e atitudes implícitos nas palavras dos portugueses e não me importo muito com a desconcordância de géneros, por exemplo. - Entrevista № 1

\section{Sobre a introspetiva}

Normalmente sucede-se a introspeção após cada sessão de diálogo, efetivamente face à forma e ao teor de diálogo, pelo que o último demonstra mais visivelmente as divergências dentro de uma comunidade de aprendizagem. Logo nos primeiros encontros, chega a perceber-se o grau diversificado de atenção colocada na presente atividade. Enquanto nos alunos chineses é fácil detetar a vontade e o entusiasmo de participação, pelos detalhes como a preparação de vocabulários até frases, os seus colegas portugueses desempenham um papel relativamente mais passivo, constatado por "falta de interesse", "relutância em pronunciar sobre algo" ou "respostas sucintas" e refletido no testemunho abaixo. Isto, indiretamente, provoca a reflexão incompleta, manifestada nos ensaios comparatistas.

Era eu quem orientava todo o diálogo, cada vez que perguntava as opiniões dela, nada, de vez em quanto lia as perguntas nos materiais, ela também respondia muito simplesmente que não sabia. As palavras que eu ouvia mais eram "depende" ou "talvez", será que os portugueses têm o hábito de responder desta forma, quer dizer, da forma eufêmica? Em todo o caso, foi uma grande confusão para mim. - Relatório reflexivo № $27,1 \underline{a}$ sessão

As introspetivas e reflexões para pós-atividade só emergem como algo importante, quando isso é explicitamente impulsionado pela formadora. Aqui é tida em consideração uma competência muitas vezes negligenciada por professores de PLA, ou seja, a competência de reflexão inserida em $\mathrm{Cl}$. Estando cada dia mais conscientes das diferenças dentro de uma 
comunidade, os alunos chineses procuram converter os preconceitos projetados na cultura de outros, de ponto de vista da maior sensibilização da "diferença entre um indivíduo e o seu agrupamento". Com este propósito, as convergências e divergências são apreciadas em peso igual, sem impedir os avanços e as lições tiradas serem igualmente refletidos, na busca de variados ângulos de interpretação e até sugestões para próximos encontros com cenários semelhantes. O aluno no excerto, com mais exercícios de reflexão, concretizou melhoramentos no diálogo e adquiriu a consciência intercultural neste aspeto.

No início, ficávamos os dois agarrados pelas respostas "sim" ou "não", tal como a questão da preferência de comida dos povos diferentes e a conclusão foi que nem duas folhas eram iguais. O fato do meu colega preferir comida picante acabou com o estereótipo que tinha guardado sobre os portugueses. Devo admitir que cada um é único, embora seja normalíssima a categorização, que facilita a nossa compreensão do mundo, também é normalíssima a dissimilitude entre indivíduos. - Ensaio comparatista № 22, 3a sessão

Essa atitude introspetiva estende-se à reflexão perante o estudo do dia-a-dia, o que justifica a autonomia crescente de aprendizagem em direção a "novos planos". Não só por meio de modificar os modos de diálogos, diante das questões concretas, mas também, talvez mais relevante, por criação de novas estratégias de aprendizagem. Por exemplo, os meios consistem, por exemplo, nas novas tecnologias de comunicação e em conversas posteriores como complemento. Esses contributos por parte dos alunos chineses para a comunidade são facilitadores da comunicação e, ao mesmo tempo, para o alívio do stresse desde os primeiros encontros.

Ao melhorar sucessivamente problemas existentes e detetar os novos, é descoberta uma diversidade alargada tanto evidente nas representações culturais como também nos modos de pensar. Sob esta perspetiva relativista, o absolutismo passa o lugar para a conetividade, dentro de um espaço convivido por todos. Os comportamentos traduzidos daí são como respeitar a privacidade, evitar a ofensa, entre outros. O maior grau de consideração dos outros transmite, de fundo, os pensamentos mais inclusivos e críticos, como são revelados no excerto abaixo, o que inevitavelmente construem uma evolução não só de $\mathrm{Cl}$, mas também de competências dos alunos na sua íntegra.

Os consensos atingidos ajudam a motivar a nossa participação na comunidade, a ter mais conversas, por exemplo. É claro que não são ausentes as desconcordâncias, que tornam ainda mais pertinente o respeito neste caso, em harmonia de um provérbio chinês "buscar a convergência enquanto reservar a divergência". As ideias individuais, normalmente limitadas por tempo e por espaço, serão completadas por ideias dos outros, que integramente beneficiam uma visão neutra e relativista. - Relatório reflexivo № 7, 4aㅗ sessão

\section{Sobre o relacionamento}

Independentemente da pertença de cada um, as etapas de familiarização são algo indispensável para qualquer tipo de relacionamento. Neste projeto, é uma constante entre todos os alunos chineses um estado psicológico pouco seguro, exemplo disso são 
testemunhos como "nervoso", "embaraçoso", "envergonhado", "grande tortura", "fora do controlo" e "falta de confiança", que eram perfeitamente previsíveis para o estágio inicial. Todavia, as atitudes demonstradas ao longo de várias sessões, inclusive os esforços por vontade e disposição inerentes, devem ser valorizadas, particularmente perante uma situação desconhecida, no sentido de ultrapassar as barreiras de comunicação. Ressaltam-se, além de incentivo recíproco e positivo dentro de comunidade, os meios de ajuste psicológico que visam maior confiança e autonomia da parte dos alunos. O excerto ilustra bem um exemplo de ajuste psicológico do aluno. Daí resultam o nível de satisfação elevado e, como consequência, as expetativas para o próximo encontro.

A impressão que tive em primeiro lugar é que ela não era uma pessoa extrovertida, muito menos faladora. Tinha sempre receio que ela se recusasse a me dar respostas assim deixando as nossas conversas meio bloqueadas. o que fiz foi, como preparação, encontrar mais tópicos possíveis e no meio de diálogo, tratá-la de forma amistosa. Depois consegui aperceber-se da sua disposição em participar, não por ser uma tarefa ou um desafio lançado por professor, mas sim para manter uma amizade verdadeira. As pausas, que continuavam a aparecer, já são vistas como desagradáveis. Ah, gosto particularmente da voz dela ao falar português, deixando-me fascinante. - Entrevista № 3

Contudo, não podemos esquecer o fato de que, apesar de tantos preparativos, física e psicologicamente, os alunos chineses continuam a experienciar os acontecimentos que afetam muito o sucesso da comunidade, os mais destacados são "pouca vontade" dos parceiros e "problemas técnicos da Internet". Só ao modificarem intencionalmente os modos de diálogos, os alunos chineses começam a adquirir as competências como "apreciar os outros" ou "simpatizar os outros". Aqui não é uma exceção a questão da variedade de nível de língua dentro de comunidade. No aspeto de aprendizagem de língua, "pedir ajuda", "ajudar-se" são declarações frequentes que justificam as opções construtivas dos alunos. A palavra-chave, nesta ocasião, reside mais na "parceria". As sensações negativas como são ilustradas no estágio inicial passam a ser substituídas por "alegria em fazer novos amigos", como é o caso do próximo excerto.

Ontem tivemos a nossa terceira sessão, na qual fisicamente não estava bem disposta. Pedi desculpas e a minha colega foi tão muito simpática e paciente que me acalmou com palavras mais fáceis e pronunciadas mais devagarinho. Foi graças à compreensão dela que foi conduzido um diálogo muito agradável. Uma grande amizade! - Relatório reflexivo № 15, 3a sessão

A amizade, tal como o relacionamento de parceria, que neste caso são mais prometidos e familiarizados, veem seus avanços ao acompanhar a descoberta de novos pontos comuns. Em grande medida, pode-se constatar a alegria ao estar acordados, ou a "empatia" entre membros de culturas diferentes, que constituem os elementos que mais salientam a evolução de $\mathrm{Cl}$. Quanto a isso, seja a língua materna seja as outras jamais se constituem o foco de aprendizagem dos alunos participantes, para quem o maior êxito se fundamenta no estabelecimento e na manutenção de relacionamento. O excerto mostra 
como esta comunidade de aprendizagem desmente preconceitos sobre a cultura portuguesa e finalmente consegue a "consonância" ou a língua comum entre os participantes.

Venho a ter a consciência de que os meus colegas portugueses se comportavam não de uma forma idêntica como o que tinha aprendido na Internet, algo que podia representar uma parte maior, mas de certeza não todos. É interessante e até engraçado que todos nós respeitamos muito o tempo e não preferimos o vinho. Isso faz-me sensibilizado da diversidade dentro de uma cultura nacional. A consonância entre nós é uma constante ao longo dos nossos diálogos, pelo que as respostas dadas entre nós são muito aproximadas, talvez porque estão a desenvolver os conhecimentos nossos em relação à cultura outra em direção ao melhor entendimento e inclusividade. Sinto-me bastante feliz por ter conseguido tudo isto, parecendo que geograficamente estamos distantes mas ao mesmo tempo pertos psicologicamente. - Relatório reflexivo № 17, 4ํㅗ sessão

\section{Discussões}

A partir da análise dos dados, propomos um modelo evolucional de $\mathrm{Cl}$, desenvolvendose de forma multidimensional, que se aproxima ao modelo composicional de $\mathrm{Cl}$. Daí é tirada a conclusão de que o modelo de $\mathrm{Cl}$ é, coexistente, evolutivo em múltiplas dimensões. $\mathrm{A}$ comunidade de aprendizagem aqui constitui um espaço onde não é parada nem sequer estável essa evolução, cujas caraterísticas foram reveladas com bastante clareza, neste estudo, através de registos de cada diálogo, particularmente na sua respetiva dimensão. Dentro da comunidade, as interação e mutualidade corresponde ao que se pede o construtivismo, tanto nos princípios como nas práticas, o que traduz numa alteração de visões perante o ensino-aprendizagem de LA. Na formação de $\mathrm{Cl}$ dos alunos de PLA, este aspecto até é mais salientado. O presente estudo conceitua a $\mathrm{Cl}$, dentro do enquadramento teórico que se diz respeito à sua conceptualização, como umas competências construídas em cenários constantemente desenvolvidos, na base de aprendizagem contínua e retrospetivas conscientes. A partir da nossa teorização, é que tentamos chegar a justificar o objetivo final da comunidade de aprendizagem na formação de $\mathrm{Cl}$, que é centrado na evolução integral de cada indivíduo.

Neste sentido e para se perspetivar a $\mathrm{Cl}$ no terreno oriental, discutimos a evolução integral de cada indivíduo com o foco colocado em relacionamentos interpessoais. Os mesmos não só servem como o meio, como também se identificam, na visão do presente estudo, como a finalidade que se pretende atingir com o desenvolvimento de $\mathrm{Cl}$, no âmbito de comunicação intercultural. A cultura oriental, sem excluir as suas outras particularidades, justifica aqui a visão holística da evolução de $\mathrm{Cl}$. Diferenciando-se das conceptualizações de $\mathrm{Cl}$ no contexto ocidental, na nossa perspetiva, as dimensões de $\mathrm{Cl}$ aparentam um panorama não só evolutivo, mas também mais interligado e interdependente. Sendo assim, reiteramos a nossa concordância com o entendimento de Carey (1989) do contexto chinês, em que a comunicação intercultural não objetiva o alargamento do espaço de transmissão de informações, mas sim a manutenção de sociedade no seu total, ou por outras palavras, a 
comunicação intercultural não reside em comportamentos em si, mas sim revela a partilha de crenças. Tomando como o exemplo a última dimensão do nosso estudo, ao longo das quatro sessões, o estabelecimento de parceria e o saber relacionar-se com os estrangeiros passam a ser prioridades dos alunos chineses na comunidade, que ao mesmo tempo se devem ser levadas em consideração na avaliação de $\mathrm{Cl}$, o fato que favorece a aplicação de instrumentos avaliativos como "portfólio", nas futuras experiências de comunidade de aprendizagem com o foco na $\mathrm{Cl}$.

O que acima foi abordado justifica uma construção de conceptualização e modelização de $\mathrm{Cl}$, mais adaptável ao contexto chinês. Uma vez que estamos cientes de que a cultura afeta a forma como se faz a perceção de $\mathrm{Cl}$ e que o paradigma dominante do estudo de $\mathrm{Cl}$ não está livre de preconceitos linguísticos, culturais ou académicos do eurocentrismo. Posto isto, Deardorff (2004), ao avançar a sua reflexão sobre a perspetiva ocidental na área, admite que uma lacuna relevante que existe é a perspetiva não-ocidental sobre o conceito de $\mathrm{Cl}$. Dai e Chen (2014) recomendam que seja bem precisa a adoção de uma abordagem específica a partir de perspetiva local.

Em articulação com o que foi abordado no Desenvolvimento de modelos de $\mathrm{Cl}$ na China, há os esforços que tentaram incorporar na conceptualização de $\mathrm{Cl}$ conceitos da cultura tradicional chinesa, à luz de exemplo, é o conceito de "harmonia" (WANG, 2017). Gao (1998) lança uma crítica ao objetivo de efetividade que está subjacente à perceção ocidental sobre o termo de $\mathrm{Cl}$, indicando que o mesmo se apresenta com uma visão pragmática em detrimento de coordenação holística. No outro trabalho dele (2002), a ideia "Tao", da cultura tradicional chinesa, foi trazida para referir aos aspetos que um deve guardar para orientar as suas ações na comunicação intercultural, e o conhecimento e as habilidades, entre outras dimensões frequentemente sugeridas, são apenas "ferramentas" ou "instrumentos", com a finalidade de conseguir as competências de "passar" e "ultrapassar".

Na base de recapitulação de argumentações de Gao (2002) e de Wang (2017), o presente estudo pretende, com a atenção colocada na $\mathrm{Cl}$ dos alunos chineses de PLA, perspetivar uma cidadania global com caraterísticas de $\mathrm{He}$ e $\mathrm{Li}$, de doutrina confuciana chinesa. Trata-se de uma postura que conjuga o modelo evolucional de $\mathrm{Cl}$ e a realidade chinesa, mais particularmente a sua sabedoria clássica que até hoje manifesta uma grande vitalidade na sociedade chinesa e que potencialmente pode ser estendida para este mundo cada vez globalizado.

Pela consideração de Chen (2011), os valores asiáticos são sumariados em cinco princípios: 1 . São mais valorizadas as sociedades e nações do que os indivíduos, 2. Famílias estão na base de nação, 3. Os indivíduos são respeitados por nação, 4. Favorece-se mais a harmonia do que o conflito com propósito de manutenção da ordem, 5. Entre as religiões pedem-se a complementaridade e a coexistência pacífica. E ao referir-se a uma valorização que propõe o conceito de harmonia e que advoga a harmonia na preservação de ordem, o autor dá especial destaque aos relacionamentos harmoniosos entre os seres humanos, algo essencial e devidamente referenciados na doutrina confuciana chinesa. No âmbito desta doutrina, ao se relacionar-se com outros, o conceito que sugerimos ter em mente é o $\mathrm{He}$, a 
palavra em chinês simbolizando a harmonia, que é classificado em cinco categorias conforme o contexto: a primeira assente na relação entre o céu e o homem, a segunda na relação entre países, a terceira entre os homens, a quarta no mundo psicológico, a quinta entre as civilizações (CHEN, 2011).

Dentro da comunidade de aprendizagem, para além da mutualidade de se relacionar, a outra conversa consiste em se especificar sobre as figuras perspetivadas de cada indivíduo no meio desse convívio. Com o propósito de evolução de $\mathrm{Cl}$, lembramos o outro conceito que dos seus carateres e manifestações se resume também numa única palavra: o $L i$, traduzida como o "Ritual" em português, em sensu lato. A recapitulação de Chen (2011) ajuda-nos a ter uma descrição minuciosa sobre o que se trata aqui. Em síntese, o Li é humanístico e não divino, o Li é dentro do mundo e não fora, o Li é civilizado e não bárbaro, o Li é comunicativo e não egocêntrico, o Li é tenro e não frio, o Li é racional e não violento, o Li é benevolente e não despótico. Acrescenta-se que, talvez nas suas interpretações menos modernas, o Li é educativo e não democrático, o Li é normativo e não crítico, o $L i$ é disciplinado e não liberal, o $L i$ é disciplinado por outros e não por si próprio, o $L i$ é obrigatório e não por direito, o $L i$ é comunitário e não individualizado. Aqui, pela ótica do estudo comparativo das propostas na sua nascença, vê-se uma grande discrepância entre os valores ocidentais e orientais. Neste aspeto, salientamos mais a educação, as disciplinas, as obrigações e a comunidade nos valores modernos, porém não menosprezando a democracia, a liberdade, a crítica e o direito que são geralmente discutidos e defendidos no mundo ocidental. É provável que não seja uma tarefa fácil a edificação desta figura ideal e que a mesma se torne um empreendimento ao longo da vida, mas é na convicção do confucionismo clássica que, com essa orientação, o Li pode ser treinado e subsequentemente estendido à vida diária e à participação na sociedade.

\section{Considerações finais}

Com o foco centralizado na evolução de $\mathrm{Cl}$ dos alunos chineses, particularmente os de PLA, o presente estudo visa vislumbrar um caminho de evolução em cinco dimensões, nomeadamente em diálogo, em comunicação, em língua, em introspetiva e em relacionamento. Essa linha de evolução, apesar de estar constrangido pela duração do projeto, não é capaz de demonstrar visivelmente o processo integral de Bennett (1993), desde a etnocentrismo até ao relativismo. Porém, não é difícil identificar que, através das quatro sessões do projeto, a $\mathrm{Cl}$ dos alunos chineses, pelos seus registos de participação, gera três passos de evolução. Sob esta prisma, cada passo, de um modo próximo ao encontro real, representa um estímulo significativo no desenvolvimento de relacionamento dentro de comunidade, o relacionamento caraterizado em primeiro pela estranheza e depois por parceria de aprendizagem, até por amizade. Pelos esforços conjuntos, os envolventes de comunidade conseguem, para além da ressonância na aprendizagem de $L A$, ter a reflexão introspetiva durante a comunicação intercultural, bem como as mudanças após reflexão, o que justamente comprova o crescimento tanto nas $\mathrm{Cl}$ como nas competências críticas. 
Nas considerações finais, reiteramos o nosso apelo para a revolução de ensinoaprendizagem de PLA na China, em direção à capacitação de $\mathrm{Cl}$ e ao desenvolvimento integral de aprendentes. A comunidade de aprendizagem em tandem, abordagem adotada nesta investigação, revela a vantagem evidente nas situações limitadas como o caso de hoje, na plena pandemia. Face à incerteza em redor à cooperação interuniversitária e internacional, a alternativa vem colmatar o fosso encontrado em programas de intercâmbio e não só, também constitui uma resposta oportuna dada à crise no ensino-aprendizagem de LA. Na era de PósCovid-19, a ideia de conexão, bem como as comunicações facilitadas por novas plataformas digitais vão nos dirigir a mudar nós próprios, professores de PLA, sobre o quê, porquê, para quê e como é que nós ensinamos.

\section{Referências}

ARASARATNAM, L. A. Research in intercultural communication: Reviewing the past decade. Journal of International and Intercultural Communication, v. 8, n. 4, p. 290-310, 2015. https://doi.org/10.1080/17513057.2015.1087096

BANKS, J. A. An introduction to multicultural education. Boston, MA: Allyn and Bacon, 1994.

BENNETT, M. J. Towards ethnorelativism: A developmental model of intercultural sensitivity. In: PAIGE, R. M. (org.). Education for the intercultural experience. 2 ed. Yarmouth, ME: Intercultural Press, 1993. p. 21-71.

BRISLIN, R. W.; YOSHIDA, T. Intercultural communication training: An introduction. London: Sage Publications, 1994.

CAREY, J. Communication as culture: Essays on media and culture. Boston: Unwin Hyman, 1989.

CHEN, G. M.; STAROSTA, W. J. Intercultural communication competence: A synthesis. Communication Yearbook, v. 19, p. 353-383, 1996.

CHEN, G. M.; STAROSTA, W. J. A review of the concept of intercultural awareness. Human Communication, v. 2, n. 1, p. 27-54, 1998-9.

CHEN, L. (陈来). 孔夫子与现代世界 [Confucius and modern world]. Beijing: Peking University Press, 2011.

DAI, X. D. (戴晓东). 跨文化能力理论发展六十年:历程与发展 [60 years of theory building of intercultural competence: development process and perspectives]. 外语界 [Foreign Language World], Shanghai, n. 4, p. 58-66, 2019.

DAI, X.; CHEN, G. M. (org.). Intercultural communication competence: Conceptualization and its development in cultural contexts and interactions. Cambridge: Cambridge Scholars Publishing, 2014.

DEARDORFF, D. K. Definitions: knowledge, skills, attitudes. In: BENNETT, J. M. (org.). The SAGE encyclopedia of intercultural competence. Thousand Oaks, CA: Sage Publications, 2015. p. $217-$ 220. 
GAO, Y. H. (高一虹). 跨文化交际能力的“道”与“器” [“Tao” and “Devices” for cross-cultural communicative competence]. 语言教学与研究 [Language Teaching and Linguistic Studies], Beijing, n. 3, p. 39-53, 1998.

GAO, Y. H. (高一虹). 跨文化交际能力的培养: “跨越”与“超越”[Intercultural communicative competence education: “crossing” and “transcending”]. 外语与外语教学[Foreign Languages and Their Teaching], Dalian, n. 10, p. 27-31, 2002.

GLASER, E.; GUILHERME, M.; GARCÍA, M. C.; MUGHAN, T. ICOPROMO, intercultural competence for professional mobility. Brussels: Council of Europe, 2007.

GONÇALVES, L. Aprendizagem intencional em tandem: os modos comunicativos na telecolaboração em língua estrangeira. In: OSÓRIO, P.; GONÇALVES, L. (orgs.). O ensino do Português como língua não materna: metodologias, estratégias e abordagens de sucesso. Coleção AILP, v. 2. Rio de Janeiro: Dialogarts, 2019. p. 16-59.

HAMMER, M. R.; BENNETT, M. J. The intercultural development inventory [instrument]. Portland, OR: Intercultural Communication Institute, 2001.

HOLMES, P.; O'NEILL, G. Developing and evaluating intercultural competence: Ethnographies of intercultural encounters. International Journal of Intercultural Relations, v. 36, n. 5, p. 707718, 2012. https://doi.org/10.1016/i.ijintrel.2012.04.010

Jia, Y. X. (贾玉新). 跨文化交际学 [Intercultural Communication]. Shanghai: Shanghai Foreign Language Education Press, 1997.

KEDIA, B. L.; MUKHERJI, A. Global managers: developing a mindset for global competitiveness. Journal of World Business, v. 34, n. 3, p. 230-251, 1999. https://doi.org/10.1016/S1090-9516(99)00017-6

KING, P. M.; BAXTER MAGOLDA, M. B. A developmental model of intercultural maturity. Journal of College Student Development, n. 46, p. 571-592, 2005. https://doi.org/10.1353/csd.2005.0060

MARTIN, J. N. Revisiting intercultural communication competence: Where to go from here. International Journal of Intercultural Relations, v. 48, p. 6-8, 2015. https://doi.org/10.1016/j.ijintrel.2015.03.008

MATSUO, C. A critique of Michael Byram's Intercultural Communicative Competence Model from the perspective of model type and conceptualization of culture. Fukuoka University Review of Literature \& Humanities, v. 44, p. 347-380, 2012.

SHEN, J. M.; GAO, Y. C. (沈鞠明, 高永晨). 基于知行合一模式的中国大学生跨文化交际能力 测评量表构建研究 [Construction of Intercultural Communication Competence Inventory for Chinese College Students Based on Knowing-and-Doing Model]. 中国外语[Foreign Languages in China], Beijing, v. 12, n. 3, p. 14-21, 2015.

SPITZBERG, B. H.; CHANGNON, G. Conceptualizing intercultural competence. In: DEARDORFF, D. K. (org.). The SAGE handbook of intercultural competence. Thousand Oaks, CA: Sage Publications, 2009. p. 2-52.

STRAUSS, A.; CORBIN, J. M. Basics of qualitative research: Grounded theory procedures and techniques. Thousand Oaks, CA: Sage Publications, 1990. 
VYGOTSKY, L. S. Mind in society: The development of higher psychological processes. Cambridge, MA: Harvard University Press, 1978.

Wang, Y. (王宇). 维度与现状:跨文化能力情感层面研究 [Components and Status Quo: a study of affective perspective in intercultural competence]. 东北师大学报 (哲学社会科学版 ) [Journal of Northeast Normal University], Changchun, v. 6, p. 39-44, 2017.

WANG, Y. A.; KULICH, S. J. Does context count? Developing and accessing intercultural competence through an interview-and model-based domestic course design in China. International Journal of Intercultural Relations, v. 48, p. 38-57, 2015. https://doi.org/10.1016/j.ijintrel.2015.03.013

Wen, Q. F. (文秋芳). 英语口语测试与教学 [Oral English test and teaching]. Shanghai: Shanghai Foreign Language Education Press, 1999.

YANG, Y.; ZHUANG, E. P. (杨盈, 庄恩平). 构建外语教学跨文化交际能力框架 [Constructing a framework for cross-cultural communication in foreign language teaching]. 外语界 [Foreign Language World], Shanghai, v. 4, p. 13-21, 2007.

ZHANG, H. Z. Avaliação de competência intercultural: estudantes universitários chineses de PLE. 2019. 320 f. Tese (Doutorado em Linguística) - Programa de Pós-Graduação em Português como Língua Estrangeira/Língua Segunda, Universidade de Lisboa, Lisboa, 2019.

Recebido em: 21/07/2020. Aceito em: 02/11/2020. 